\title{
Propeller Design Requirements for Quadcopters Utilizing Variable Pitch Propellers
}

\author{
Ian R. McAndrew, Elena Navarro, and Ken Witcher
}

\begin{abstract}
Unmanned aerial vehicles, UAV, has increases in the drastically in these past several years since their costs reduced. This research is based and built upon previous research presented in a conference. With the advent of commercial Quadcopters, four propeller systems, are used, being designed and used to operate the advantages of both flight and hovering. The basic design of their propeller blades has not evolved from the early days of manned flight when wooden fixed blades were used. In this paper that expands upon previous findings and discussions it explores the historical developments. Furthermore, how the expansion and reduction in costs of modern materials and manufacturing techniques that offer more accurate matching of blades' needs and applications.
\end{abstract}

Index Terms-Aerodynamics, blade design, efficiency and flight stability.

\section{INTRODUCTION}

Student of aviation are aware from early studies of Kitty Hawk on the $17^{\text {th }}$ December, 1903, the Wright Brothers first undertook powered man-flight. This epoch stands alongside the first time man broke the speed of sound and landing on the moon. Now set as a seminal date for what is known as Aviation and a complete new mode of transportation that has changed to world in many different ways. Within 66 years man set-off by a rocket to walk on the moon and returned safely. Technology usually advances at rapid paces when it offers commercial possibilities, opportunities or War dictates the necessity for advantages.

The UAV market is built upon innovation and parallels can be drawn between the start of manned flight and UAV flight. In 1903, the parallels stop as all technology was new and not borrowed for other designs. In Fig. 1 below, is the first aircraft flying, a modest height (altitude) nowadays but then it was leading edge science [1]. Low level and speeds resulted in flight instability problems as sufficient altitude and time not available for pilots to recover and many fatalities happened. The success of the Wright Brothers flight was in part mainly to the sufficient thrust generated to first achieve flight and a speed sufficient to generate lift greater than the weight, then more to achieve a height for travelling a distance.

Basic thrust was generated by a simple fixed pitch propeller made from various laminated wood, see Fig. 2, below [2].

Manuscript received January 11, 2017, revised March 5, 2017

I. R. McAndrew is with the College of Aeronautics, Embry Riddle Aeronautical University, Worldwide, U. K. (e-mail: mcand4f1@erau.edu).

E. Navarro is in the Department of Arts and Sciences, College of Aeronautics, Embry Riddle Aeronautical University, Worldwide, Germany (e-mail: navarrj1@erau.edu).

K. Witcher is the Dean of the College of Aeronautics, Embry Riddle Aeronautical University, Worldwide, Fl. USA (e-mail: witchea8@erau.edu).
This basic design was in its infancy but sufficient for the needs of early flight.

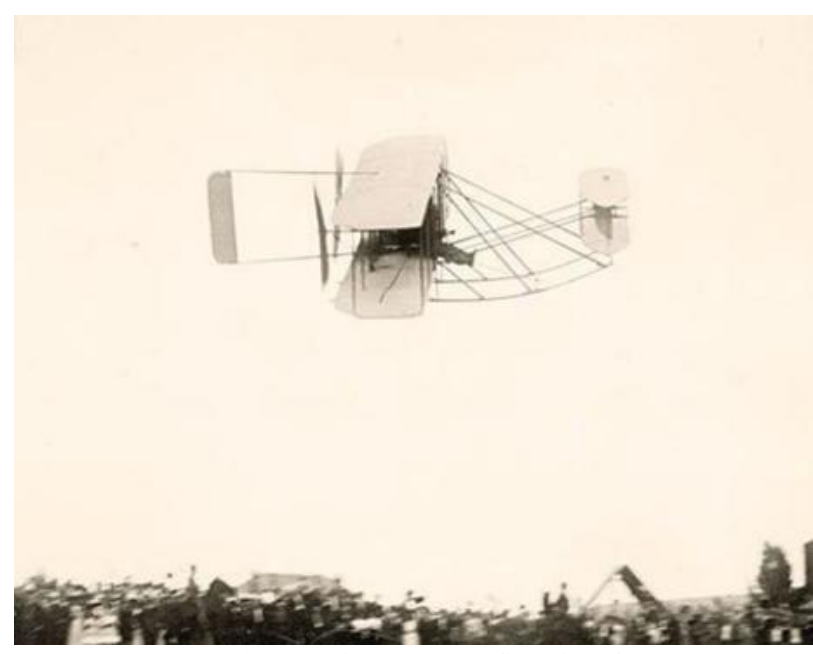

Fig. 1. Wright Brothers first aircraft.

The basic design of propeller was crude but worked, the science was unclear and the subsequent research offered more efficiencies, to be discussed later in this research paper. As such, sufficient thrust was produced to accelerate the aircraft for flight [3].

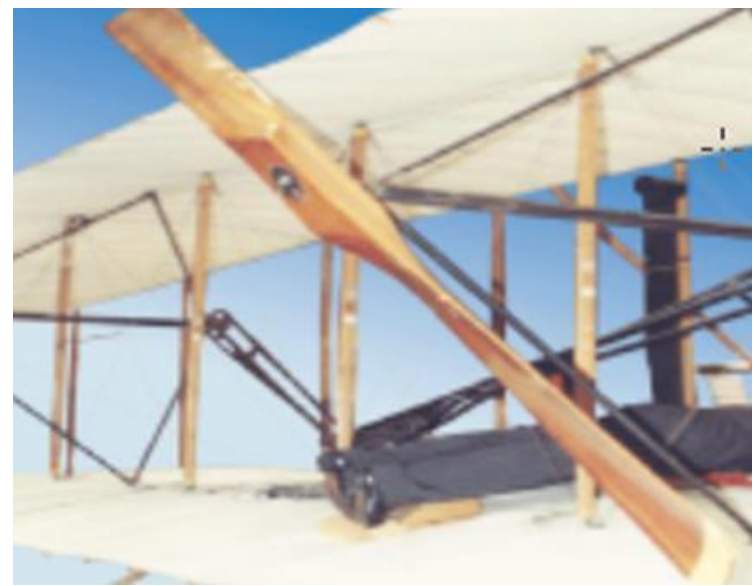

Fig. 2. Wright Brothers fixed pitech twin bladed propeller.

Starting with current UAV designs, if a propeller is selected from a current search of those commercially available it will result in the ones shown below in Fig. 3. They are no longer made from laminated wood, but various types of injected plastics and composite or high carbon fibre materials. What is demonstrated is that there is little or no difference between those used originally in the early days of powered flight and those now for Quadcopters [4], both are fixed pitch propellers designed for maximum efficiency in acceleration of top speed. 


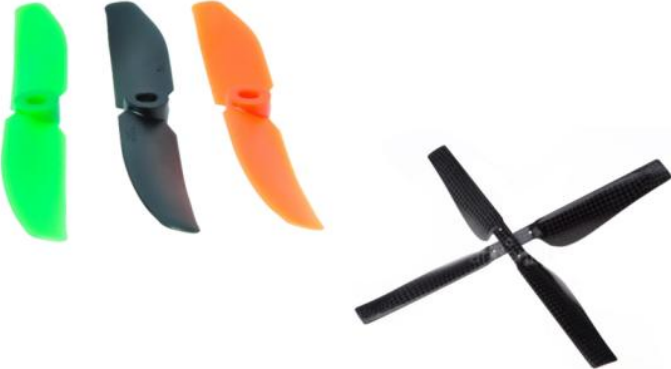

Fig. 3. Plastic fixed pitch propellers for Quadcopters.

Modern propellers may now be waterproof and of various colours, they are however, practically identical in design and application, if not subject to the same failures in use.

Blade pitch is a critical parameter for a propeller. The pitch is in effect how much air is cut by the blade and you can liken to the gears on a manual car gearbox. The pitch set for initial acceleration (needed to take-off) but fixed and the speed in fixed blade pitch is limited by this. You could, however, set the blade pitch for maximum speed in flight. This would require a very long runway to slowly gather speed sufficient for enough lift for flight [5]. Generally, they are set at a compromise where take-off not maximized and maximum speed below that possible.

Fixed pitch designs limited the initial aircraft speeds and engineers researched the science behind the propeller thrust. The next stage in propeller development was two positioned propeller blades. Position 1 is set for take-off and position 2 for maximum cruise speed. In Fig. 4 below, is shown an example from a DC-3 that was extensively used throughout the World War II.

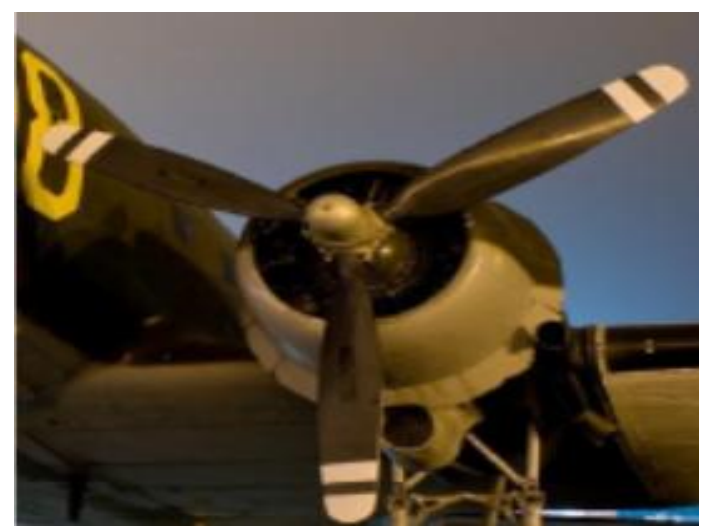

Fig 4. Twin pitch propeller on a DC-3 aircraft.

Two pitch propellers allowed for optimum angle of attack, AoA, on take-off and then switch to optimum AoA on cruise. Climb and descend or other unscheduled maneuvers were always a compromise. When this became available then the flight maximum cruise speed almost doubled and large distances could be covered in half the time of fixed propellers, and equally important, with a lower fuel demand; thus longer endurance flights between refueling. At this stage the opportunities opened up for commercial transportation and ones where operators could make profits to off-set the high startup costs in aviation.

Blade developments have continued and they are very technically different from older ones, see Fig. 5 below is an example of one of one of the most advanced propellers used [6]. This is a seven bladed, composite and multi-geometric position, propeller system

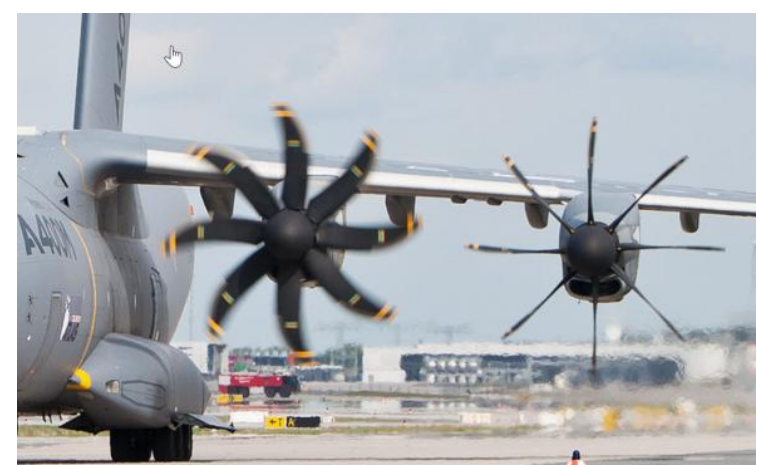

Fig. 5. Multi bladed multi-geometric bladed variable pitch.

Above shows the propellers in their two unique positions. On the right it is in the 'feathered position' and this position eliminates any load applied to the engine when not in use on the ground or if it stops working in-flight. The left hand position is in taxi idle, as dictated by alpha and beta settings for low power whilst taxing.

\section{Modern DAY VARIABLE PITCH PROPELLERS}

Above the compromises that were available to use in operation was discussed. Fig. 6 below, is a graph showing how efficiency will depend on certain factors.

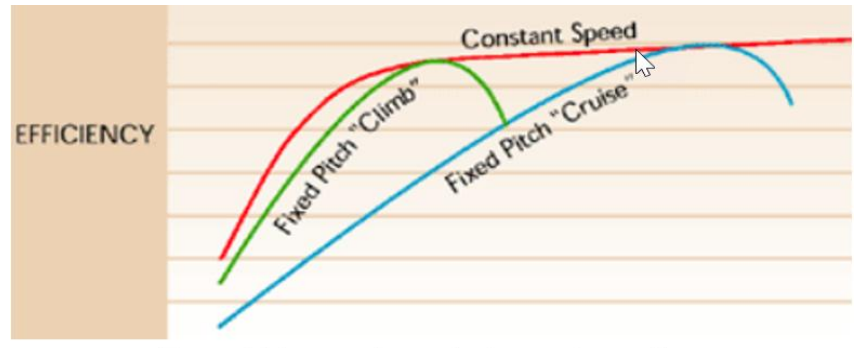

For variable speed, constant speed propellers

Fig. 6. Efficiency v. speed for blade positions.

Setting the pitch at a fine AoA (low angle) the acceleration is best, maximum efficiency is reached then reduces thereafter. Alternatively, when set for maximum cruise speed there is an efficiency point that exceeding anything beyond it drops in efficiency. Loss of efficiency reduces the potential range, its maximum take-off weight, etc. Excessive vibrations and reliability concerns to the structure of the frame might occur when higher rpm are used to compensate accordingly.

The fixed Climb and Cruise are for propellers where the $\mathrm{rpm}$ is increased to generate the needed thrust. As speed increases the blade tips might approach the speed of sound. This is not desired as induced vortices and the wake generate excessive vibrations that shake the propeller and potentially it will brittle fracture from over stressing [7]. Propellers now operate with a constant speed system that means the maximum tip speed not approach higher transonic speeds. They rotate at one defined speed and power is increased by additional fuel and pitch position whilst acceleration is optimised by the blade angle set to fine. There are three principal positions and these are summarized clearly below in Fig. 7 and used for the principal operations of take-off, cruise and engine start-up on gas turbine systems. 


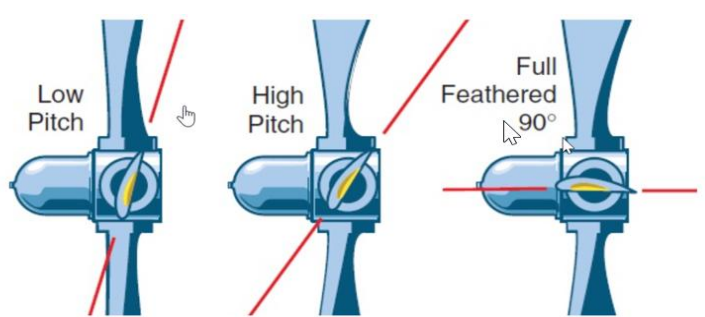

Fig. 7. Three principal positions of a variable pitch propeller.

Low or fine pitch is a position used for acceleration at take-off, when maximum thrust is needed. At cruise the need is the pitch, it is set to high pitch (also called course pitch). The third position is for when the engine is not running, when idle after engine start-up on gas turbine systems or if the engine stops working in flight. This position will ensure no loads are applied to the engine when it rotated by external forces [8]. The first two positions of the engine power (thrust) is available to be used to suit piloting demands, the third position is for practical protection of the engine. For example, if the engine mechanically stopped in flight; then the air would turn the propeller and this might result in applied loads internally on the bearing, when no pressure available to lubricate.

There are alternative blade positions that may be selected by the pilots, these are show in Fig. 8 and include commonly known as Alpha and Beta positions. Alpha is set by the pilots in-flight to maximise the efficient use of available thrust for cruise [9]. Note that the engine is operated at a constant speed regardless of flight requirements. Alpha range is operated by a pilot with a dedicated lever in the cockpit for in-flight, cruise, requirements. In theory there is an infinite number of positions from the lowest alpha to highest Beta value. Beta values are to set at ground idle and where the AoA of the blade face is below zero, thus, there will be no forward thrust and a reverse thrust generated. Reverse thrust is applied in lieu of breaking when landing and can be recongnised by the sudden increase in sound when a passenger in a turbo-prop aircraft. On float-planes this affords the pilot a reversing ability to move the aircraft backwards and alignment for take-off. These Alpha and Beta positions offer the pilot full control over the power available and when needed for all applications of flight. They are, in effect, the optimum for propellers and represent what is the most advanced level and operation.

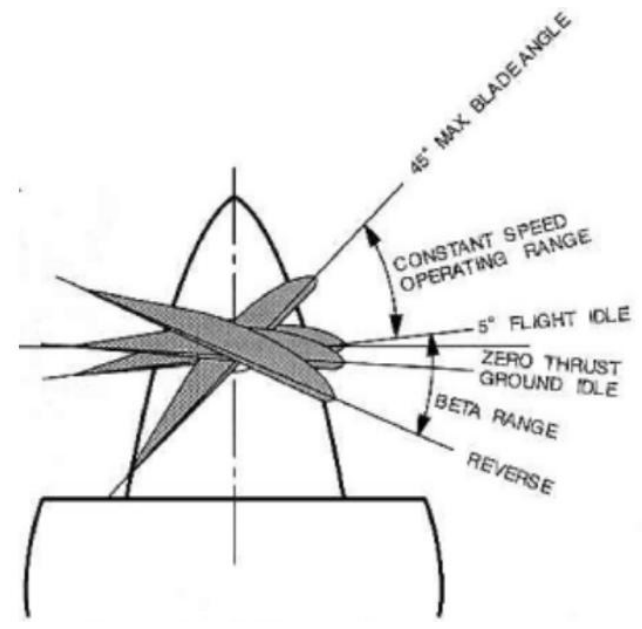

Fig. 8. Alpha and Beta positions for propellers.
Currently, the positions can be dictated by the pilot or the lever systems and may inform the pilot optimum settings for each stage of flight plan. For a UAV this might be automatically controlled give processing power and costs.

\section{QUADCOPTER PITCH POSITIONS}

Quadcopters have four sets of propellers to generate the lift and movement, two rotate clockwise and the other two anti-clockwise to balance the torque produced, see Fig. 9 below. As with any early aircraft, increased thrust is achieved by increasing the rpm of the engine. Thus, at vertical take-off the speed increases from idle to generate lift, the higher the speed the higher the lift and hence altitude [10]. To hover the speed is manually adjusted to generate lift sufficient to the load of the UAV - equilibrium - and requires manual dexterity. To land the speed is reduced so the lift is less than load and the decent speed is related to rate of decent needed [11].

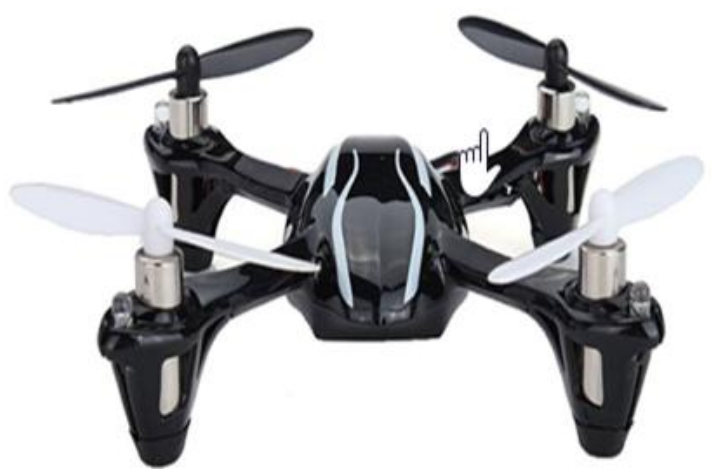

Fig. 9. Typical Quadcopter.

Propellers for Quadcopters are relatively small in diameter than most commercial aircraft applications. With these propellers they are limited by the speed of sound at blade tips. If a propeller has a diameter of $300 \mathrm{~mm}$ it would need to have a rpm in excess of 39,000 . Speed control of upper speed is considered not an operational problem when you consider maximum motor speeds are substantially below this value. Close examination of the blades and they are of the same design as early aircraft shown in the beginning of this paper in Fig. 3. Fixed propeller positions are designed for acceleration (vertical take-off) or efficient horizontal movement [12]. Likewise, some might be a compromise on both inputs. Regardless, they will not be working at their maximum efficiency

Quadcopters are often powered by removable batteries, they have a maximum output of energy available at each terminal, any inefficiency will either limit take-off load or endurance, maybe both [13]. It is paramount for them to be efficient to enter the next stage of commercial application.

\section{COMMERCIAL APPLICATIONS}

There has been a lot of discussion on applications for UAVs other than the military applications or Fire \& Rescue work [14]. There are many suggestions that humanitarian applications will be the next stage of their use. Somewhat like 
early aircraft where in War or postal deliveries in the mid-west of America post war when many pilots and cheap aircraft available.

Modern day versions of mail delivery could be possible if legislation was changed. Online deliveries from central warehouses or between central warehouses is the most likely. Many might argue that their use in commercial airspace is the problem, but NEXTGEN is addressing these needs and non-commercial, GA, airspace is already available. Below in Fig. 10 is a prototype Quadcopter for delivering parcels [15].

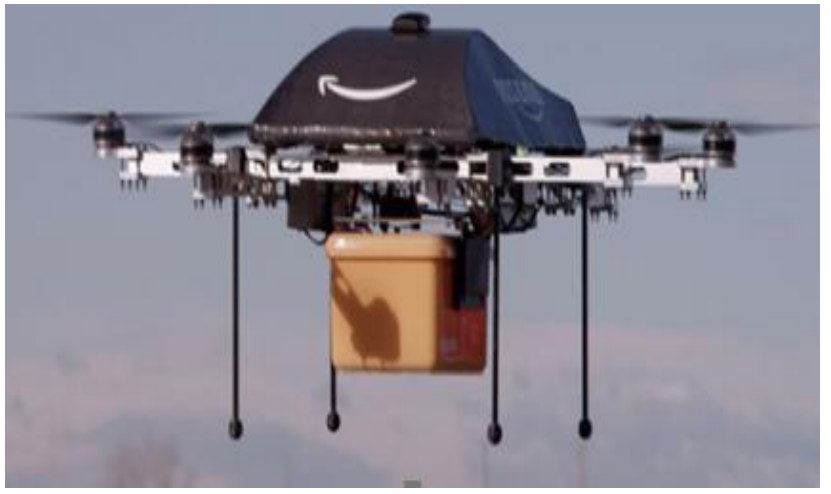

Fig. 10. Prototype parcel delivery Quadcopter.

The dropping off goods, distributing are all basic engineering problems that have solutions. Battery life is the limiting factor for making commercial success, unless local charging points are possible. It is paramount to use the battery efficiently until long-life batteries are available. Thus, using available power efficiently for take-off and hovering even more important. As stated above, fixed pitch propellers do not allow for that and the need to use known solutions to propeller design with individual applications more critical.

In addition to the battery life is flight stability and control. One of the most difficult problems in all flight is a controlled vertical height-reduction on approaching landing. The landing forces are quadratically increased and if vertical speed doubled the force on landing is therefore quadrupled. Given that, the parcel may be delicate or sensitive to shock loads this is a problem. Currently the speed of the propellers is slowed to generate lift slightly below the load valve. The feedback to this now is visually observing. If remotely or self operated then more complexities, if automatic then sensors to detect vertical speeds needed (added weight and complexity). A variable pitch propeller system offers many opportunities to control the decent at a level acceptable and ultimately controllable. For example, two rotors might be kept to generate lift for hovering while the other two apply a reverse thrust of minimum level to combine for controlled decent. There are other possibilities not addressed in this paper to apply basic aerodynamics to find solutions for all movement needs.

\section{PROPELLER SPEEDS}

Early fight speeds were slow buy any yardstick, the Wright Brothers Flyer 1 had a maximum forward speed of 30mph and even those in the First World War (Sopwith Camel) just exceeded the $100 \mathrm{mph}$ barrier. These were all fixed pitch propellers, below in Fig. 11 is a graph showing how speeds increased during the early years as propeller designs improved.

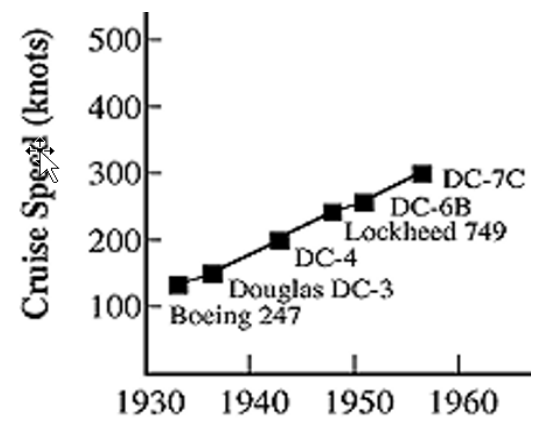

Fig. 11. Aircraft speeds in the early days of propellers.

From 1903 until the end of the First World War speeds increased marginally and remained at $120 \mathrm{mph}$ through most of the 1920s. The Boeing 247 when first introduced had a cruise speed of approximately $140 \mathrm{mph}$. The subsequent B 247D model introduced the one of the first variable pitch propeller and achieved cruise speeds in excess of $180 \mathrm{mph}$ and even reaching $210 \mathrm{mph}$.

The increase in speed became important and as engines were more powerful and efficient; the ranges increased substantially. The DC 7 when first introduced, see Fig. 12 below, reached in excess of $300 \mathrm{mph}$, with development the cruise speed was over $350 \mathrm{mph}$ and reached $400 \mathrm{mph}$ with a range of 5000 miles.

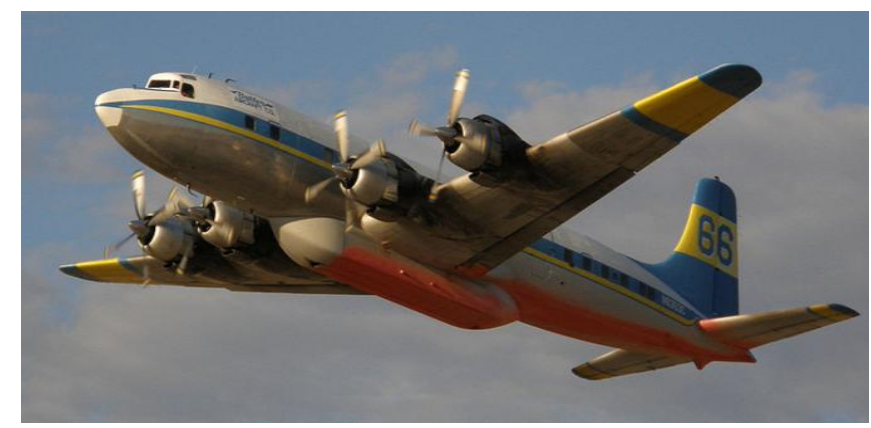

Fig. 12. DC 7C

There were four engines each with variable pitch propellers and the maximum speeds achieved were only superceded with the advent of thecommercial jet engines used for the De Havilland Comet and B 707. The speeds achieved with this design and configeration are simiar to modern Turbojet aircrafts, e.g., DH -Dash-8.

Propellers have reached close to the maximum epecations now, they are more efficient for flights in the 20,000 ft altitude and relatively shorter distances with Turboprop engines. The theory of propellers is extensive and substatntially more advances than the first fixed pitch ones used up to the early 1920 s or thos on simple general private aviation ones now.

\section{UAV EXPECTED REQUIREMENTS}

UAVs are now operated remotely by controls that are either within the visual line of flight, VLS, or outside the visual line of flight, OVLS. There are two principal aspects that need to be addressed. First, the efficient use of a battery and secondly 
by having more control in vertical accent and especially decent. This paper proposes the use of variable pitch propellers to address these two aspects [16]. Fig. 13, below is shown the real aim of the next generation of Quadcopters where products are delivered from source to end user.

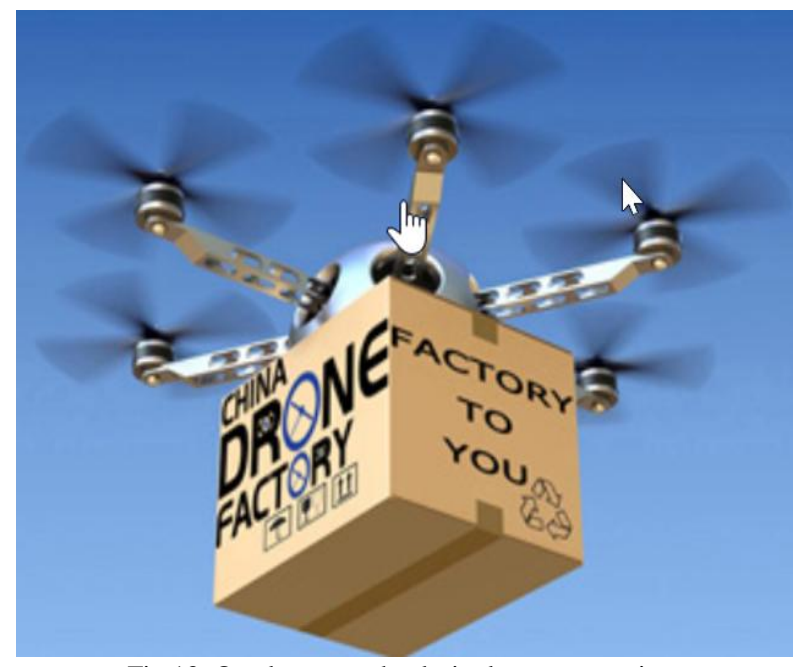

Fig 13. Quadcopter - the desired next generation.

Current variable pitch propellers have their speed controlled by a mechanical/hydraulic governor that stops over run and also underrun. A UAV will need electronic governance of individually for each of the four propeller blades. This paper has not address control systems; nevertheless, the situation is that the aerodynamic theory and application does exist. In the time honored tradition of Soichiro Honda (1906-1991) ADOPT, ADAPT and IMPROVE. This can be the principal for UAV Quadcopters to their next level of usage. There are implications, for example, an Alpha and Beta level on the remote or automatic system [17].

\section{NEXT STAGES OF RESEARCH}

To achieve these requirements several stages are needing research and solutions identified. As mentioned earlier, this builds upon previous research and publications, that form a line of needs. Variable pitch blades that can be controlled electronically, speed governors are too complex and heavy, and an electronic solution similar to hard drive speeds in computers. Variable pitch blades designed to suit applications, e.g., speed, payload that are aerodynamics clarified for variable pitch quadcopters blades. Finally, evaluating how we can design a quadcopter to incorporate these and offer parallel success with modern propeller blade use.

\section{FUTURE RESEARCH}

Research will follow a core direction and can be divided accordingly: Aerodynamics of small variable pitch blades; blade design evaluations; and electronic controls for constant speed and sync as in multi-propeller aircraft to achieve stability

Aerodynamics of blade design with be with low Reynolds numbers and the influence of bend and twist on geometry during changing pitches. They will need to be flexible, but how much strength is needed must be first established.

Material strengths and blade design, including manufacture to ensure rigidity but lightweight. Composites and thermosetting plastics are the main materials being researched.

Finally, constant speed control is a separate research project between the lead author and a different group of researcher.

\section{CONCLUSION}

Aeronautical engineering of propellers has constantly faced its design challenges to improve efficiencies and operational usages. Variable pitch propellers are no exception and the development of these have been clarified with their applications. Quadcopters have parallels in their development and by benchmarking to known areas there are already solutions that only need adapting. If UAV Quadcopters are to be used, then maximizing their operational efficiency is critical. Constant speed propellers with variable pitches will increase take-off loads, range, flight and landing stability. Why reinvent the wheel when applications exist that only need adopting?

\section{ACKNOWLEDGMENT}

This feasibility study was developed and encouraged by users and practitioners of UAV Quadcopters and we would like to thank personally Dr. B Terwilliger for his insight and recommendations to make this a seminal work. The authors are aerodynamicists and a mathematician. There next stage is to model the stability and power requirements for constant speed blades used with Quadcopters.

\section{REFERENCES}

[1] Federal Aviation Administration. (2015). Unmaned aircraft systems civial operations (non-governmental). [Online]. Available: https://www.faa.gov/uas/civil_operations/

[2] H. H. Perritt and E. O. Sprague, "Drones," Vanderbilt Journal of Entertainment and Technology Law, vol. 17, no. 3, p. 673, 2015.

[3] R. J. Kephart and M. S. Braasch, "See-and-avoid comparison of performance in manned and remotely piloted aircraft," IEEE Aerospace and Electronic Systems Magazine, vol. 25, no. 5, pp. 36-42, 2010.

[4] Pilots' failure to see and avoid caused 2007 news helicopter collision, Aircraft Engineering and Aerospace Technology, vol. 81, no. 3, 2009.

[5] European Aviation Safety Agency. (2015). European aviation safety agency - civil drones. [Online]. Available: https://easa.europa.eu/easa-and-you/civil-drones-rpas

[6] M. R. Koerner, "Drones and the fourth amendment: Redefining expectations of privacy," Duke Law Journal, vol. 64, no. 6, p. 1129, 2015.

[7] R. Sternberg and K. Sternberg, Cognitive Psychology, Boston: Cengage Learning, 2016.

[8] E. Sapir, 1964, Culture, Language, and Personality, Berkeley, CA: University of California Press.

[9] B. Whorf, 1956, Language, Thought, and Reality: Selected Writings of Benjamin Lee Whorf, J. B. Carroll Ed., Cambridge, MA: MIT Press.

[10] A. Mooney, "Co-operation, violations, and making sense," Journal of Pragmatics, vol. 36, no. 5, pp. 899-920, 2004.

[11] H. Sacks, E. Schegloff, and G. Jefferson, "A simplest systematics for the organization of turn-taking for conversation," Language, vol. 50, pp. 696-735, 1974.

[12] C. Linde, "The quantitative study of communicative success: Politeness and accidents in aviation discourse," Language in Society, vol. 17 , no. 3, pp. 375-399, 1988. 
[13] J. Sexton and R. Helmreich, "Analyzing cockpit communications: The links between language, performance, error, and workload," Journal of Human Performance in Extreme Environments, vol. 5, no. 1, 63-68, 2000.

[14] I. R. McAndrew, A. Carruthers, and E. Navarro, "Hypersonic unmanned aerial vehicles: A case for rapid deployment of specialised cargo," 2014.

[15] S. A. Beebe, S. J. Beebe, and M. V. Redmond, Interpersonal Communication: Relating Toothers, 7th ed. Upper Saddle River, NJ: Pearson, 2014

[16] T. Tiewtrakul and S. R. Fletcher, "The challenge of regional accents for aviation English Language proficiency standards: A study in difficulties in understanding in air traffic control-pilot communications," Ergonomics, vol. 53, no. 2, pp. 229-239, 2010.

[17] International Journal of Unmanned Systems Engineering, World Congress on Unmanned Systems Engineering, vol. 2, no. 3, pp. 80-85, University of Oxford, Oxford, UK, 30th July - 1st August.

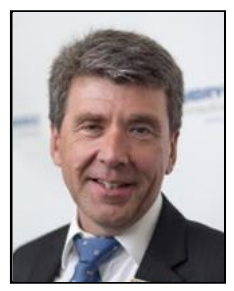

Ian R. McAndrew is the department chair for Embry Riddle Aeronautical University - Worldwide, College of Aeronautics. He has a $\mathrm{PhD}$, master's and undergraduate degree in mechanical engineering. In addition, a master's in education and another undergraduate degree in manufacturing. He lives and works in the UK, where all his degrees were awarded. Dr McAndrew is also a Chartered Electrical Engineer. His current research interests are in low speed aerodynamics and the statistics of reliability in design.

Before entering education, he worked in the Automotive industry where he held several patent for automation of engine assembly and manufacture. $\mathrm{He}$ is the author of several books and conference proceedings. Additionally, he has examined PhD globally and has taught in more than 20 countries during his academic career.

Dr. Ian R. McAndrew PhD FRAeS is a professor of Aeronautics at his university and tenured. He is a member of several institutions and external examiner at two UK Universities. 